\title{
Increased Total Renin Levels but Not Angiotensin-Converting Enzyme Activity in Obese Patients with Polycystic Ovary Syndrome
}

\author{
Ziynet Alphan Zehra Berberoglu Suheyla Gorar Zehra Candan Aynur Aktas \\ Yalcin Aral Esranur Ademoglu \\ Department of Endocrinology and Metabolism, Ankara Education and Research Hospital, Ankara, Turkey
}

\section{Key Words}

Polycystic ovary syndrome · Angiotensin-converting enzyme $\cdot$ Renin

\begin{abstract}
Objective: To investigate the renin-angiotensin-aldosterone system and angiotensin-converting enzyme (ACE) activity in patients with polycystic ovarian syndrome (PCOS). Subjects and Methods: In this case-control study, 41 obese (PCOS) women and 29 healthy controls, matched for age and body mass index, were enrolled. Anthropometric, metabolic, and hormonal patterns, including plasma aldosterone, plasma renin, and ACE activity, were measured in each subject. Results: Plasma renin levels were significantly higher in PCOS patients $(19.7 \pm 14.5 \mu \mathrm{g} / \mathrm{ml})$ compared with controls $(12.9 \pm 9.0 \mu \mathrm{g} / \mathrm{ml}$, $p<0.05)$. ACE activity and aldosterone levels did not significantly differ between both groups $(p=0.15$ and $p=0.18$, respectively). Analysis of PCOS patients showed a significant correlation of fasting insulin levels with levels of renin $(r=0.305$, $p<0.01)$ and free testosterone $(r=0.384, p=0.001)$. Similarly, homeostasis model assessment index was positively correlated with total renin concentrations $(r=0.366, p<0.01)$ and free testosterone $(r=0.352, p<0.01)$. Conclusion: Obese PCOS women had higher total renin levels, but not ACE activity and aldosterone levels, related to insulin resistance compared with controls.

Copyright ๑ 2013 S. Karger AG, Basel
\end{abstract}

\section{Introduction}

Polycystic ovarian syndrome (PCOS) is one of the most common endocrine disorders affecting women of reproductive age. The hallmarks of this syndrome are anovulation, androgen excess, and insulin resistance (IR) [1]. The pathogenesis of PCOS is complex and multifactorial. Androgens and insulin are two key molecules whose interaction appears to be amplified by several different mechanisms, notably in both directions. The IR accompanied by compensatory hyperinsulinemia in PCOS has been characterized by a postbinding defect in the insulin receptor-mediated signal transduction in adipocytes and skeletal muscle [2]. Hyperinsulinemia contributes to hyperandrogenism and ovarian dysfunction. Insulin augments the ovarian theca cell androgen production through acting directly or synergistically with luteinizing hormone (LH) [3]. It also inhibits hepatic synthesis of sex hormone-binding globulin, thereby increasing free testosterone levels [4]. Conversely, testosterone may cause hepatic IR through facilitating catecholaminestimulated lipolysis in visceral adipose tissue and exposing the liver to a high flux of free fatty acids [5].

The mechanisms implicated in the development of IR remain incompletely understood. Reactive oxygen species (ROS) are a common underlying mechanism involved. Furthermore, there is a close association between

\begin{tabular}{ll}
\hline KARGER & $\begin{array}{l}\text { () 2013 S. Karger AG, Basel } \\
1011-7571 / 13 / 0225-0475 \$ 38.00 / 0 \quad \text { Karger }\end{array}$ \\
$\begin{array}{l}\text { E-Mail karger@karger.com } \\
\text { www.karger.com/mpp }\end{array}$ & $\begin{array}{l}\text { This is an Open Access article licensed under the terms of the } \\
\text { Creative Commons Attribution-NonCommercial 3.0 Un- } \\
\text { ported license (CC BY-NC) (www.karger.com/OA-license), } \\
\text { applicable to the online version of the article only. Distribu- } \\
\text { tion permitted for non-commercial purposes only. }\end{array}$
\end{tabular}

Zehra Berberoglu, MD

Ankara Education and Research Hospital

Department of Endocrinology and Metabolism

Şükriye Mh, TR-06340 Sihhıye, Ankara (Turkey)

E-Mail zehraberberoglu@gmail.com 
IR, excessive production of ROS and inappropriate activation of the renin-angiotensin-aldosterone system (RAAS). The RAAS-associated signaling by way of the angiotensin II (Ang II) type 1 receptor and mineralocorticoid receptor promotes overproduction of ROS through tissue activation of the nicotinamide adenine dinucleotide phosphate-oxidase [6]. Additionally, RAAS activation results in increased production of Ang II and aldosterone, both of which induce degradation of insulin receptor substrate-1 via ROS-mediated signals. Thus, Ang II and aldosterone may be involved in the pathogenesis of IR via oxidative stress $[7,8]$.

The RAAS components are locally expressed in human adipose tissue. Plasma levels of aldosterone increase in conditions of abdominal obesity and IR. Body mass index (BMI) is positively correlated with plasma aldosterone concentrations, independent of age, blood pressure, gender, and sodium intake, in both normotensive individuals on a high-sodium intake and overweight-obese patients with essential hypertension $[9,10]$. This relationship suggests a pathophysiological link between the synthesis and/ or secretion of aldosterone and rising adiposity. Plasma renin activity and angiotensin-converting enzyme (ACE) also correlate positively with BMI in obese patients [11]. Angiotensinogen and mineralocorticoid-releasing factor have been shown to be secreted from visceral adipose tissue $[12,13]$. Thus, fat deposition may lead to elevation of plasma renin activity [14]. Conversely, angiotensinogen and Ang II produced in adipose tissue have been shown to promote adipocyte tissue growth [15]. Furthermore, aldosterone may be involved in determining fat deposition, as it promotes white adipose cell differentiation through acting on the mineralocorticoid receptor to induce peroxisome proliferator-activated receptor- $\gamma$ mRNA expression [16].

Based on these considerations, the present study was carried out to investigate RAAS and ACE activity in obese patients with PCOS.

\section{Subjects and Methods}

The study was approved by the local Institutions Ethics Committee of the hospital. All participants provided written informed consent before they were enrolled in the study.

\section{Subjects}

Forty-one obese women with newly diagnosed or untreated PCOS and 29 controls matched for age and BMI were enrolled in the study. Using the revised Rotterdam criteria (Rotterdam ESHRE/ASRM-sponsored PCOS Consensus Workshop Group 2004), PCOS was defined as the existence of at least two of the following three features: oligomenorrhea or amenorrhea $(<6$ men- strual cycles for each year), clinical or biochemical signs of hyperandrogenism (as determined by serum hormonal concentration, and Ferriman-Gallwey score), and polycystic ovaries [17]. The enrolled subjects were normotensive, and not suffering from chronic or acute disease. The sample size was chosen based on the study feasibility. Post hoc power analyses demonstrated that the sample size was adequate to achieve a greater than $80 \%$ power for all statistical tests.

Inclusion criteria for the control group were regular menses (every 28-30 \pm 2 days, progesterone levels $>5 \mathrm{ng} / \mathrm{ml}$ during two subsequent cycles) and absence of hyperandrogenism. Exclusion criteria were pregnancy, androgen-secreting tumors, Cushing's syndrome, congenital adrenal hyperplasia, hyperprolactinemia, thyroid dysfunction, neoplastic, metabolic, or cardiovascular disorders or other concurrent medical illness (including acute or chronic infection, hypertension, diabetes, sarcoidosis or kidney, liver, autoimmune, cerebrovascular, and ischemic heart disease); current or previous (within the last 6 months) use of oral contraceptives, glucocorticoids, antiandrogens, ovulation induction agents, or antidiabetic, antiobesity, and antihypertensive drugs; or use of anti-inflammatory drugs and other hormonal drugs during the last month; tobacco use or alcohol intake, and intense physical activity.

\section{Methods}

Before the study, all subjects received a regular salt diet containing 10-13 g of sodium chloride $(\mathrm{NaCl})$ daily for a week. At study entry, all subjects underwent a complete clinical examination, anthropometric measurements, and laboratory tests. Laboratory parameters included a complete hormonal analysis including renin and aldosterone values, fasting glucose and insulin levels, the homeostasis model assessment (HOMA) index, lipid profile, serum sodium and potassium, and ACE activity.

All blood samples were obtained in the morning between 08.00 and $09.00 \mathrm{~h}$ after an overnight fasting, during the early follicular phase (cycle days 2-5) of a spontaneous or progestin-induced menstrual cycle. Aldosterone and renin blood samples were obtained after 2-hour upright position. This procedure was adopted because Sealey et al. [18] demonstrated that the initial rise in LH preceded the initial rise in plasma prorenin and renin during the menstrual cycle.

\section{Biochemical Assays}

Plasma glucose levels were assayed by the glucose hexokinase method. Serum fasting insulin levels were measured by microparticle enzyme immunoassay on an AXSYM immunoanalyzer (Abbott Laboratory, Abbott Park, Ill., USA). Serum gonadotropins (LH, follicle-stimulating hormone), estradiol, total testosterone and prolactin were determined by chemiluminescent microparticle immunoassay on an Abbott-ARCHITECT Immunoanalyzer (Abbott Laboratory). Free testosterone was analyzed by the radioimmunoassay (RIA) kit (DSL-4900). Cortisol levels were assayed by electrochemiluminescence immunoassay method with Roche kits, using E-170 (Roche). 17-Hydroxyprogesterone was measured by the Biosource 17- $\alpha$-OH-RIA-CT kit (Biosource International, Camarillo, Calif., USA). Serum dehydroepiandrosterone sulfate was determined by competitive chemiluminescent enzyme immunoassay (DPC Immulite 2000).

Serum ACE activity was measured by a colorimetric method. Aldosterone and total renin concentrations were measured by a RIA method (Immunotech, Prague, Czech Republic). 
Statistical Analysis

Homogeneity of variances was analyzed using Levene's test. The normality of the distribution of the variables was assessed by using the Shapiro-Wilk test. Normally distributed variables were compared between groups using Student's t test. The results are expressed as the number of observations ( $n$ ) and mean \pm standard deviation (SD). Assumptions of parametric tests were not available for some variables, so the comparisons of these variables were performed with the Mann-Whitney $U$ test. The results of nonparametric tests are presented as mean $\pm \mathrm{SD}$, median, minimum and maximum values. The Pearson product-moment correlation coefficient was used to show the relationships between normally distributed variables. Spearman's rho rank correlation coefficient was employed to evaluate the correlations between nonnormally distributed variables. Data analyses were performed using the Statistical Package for the Social Sciences, version 15.0 (SPSS Inc., Chicago, Ill., USA). A p value $<0.05$ was considered statistically significant.

\section{Results}

The demographic and biochemical data of the PCOS and control groups are given in table 1 . Both groups were matched for age, BMI, and waist-to-hip ratio. Fasting glucose and insulin levels, and HOMA-IR were similar in both PCOS and control groups. Serum sodium and potassium levels were not significantly different between both groups ( $\mathrm{p}=0.51$ and $\mathrm{p}=0.48$, respectively).

The hormonal profiles of both patients with PCOS and controls are given in table 2 . The women with PCOS had significantly higher $\mathrm{LH}$, total and free testosterone, and DHEA-S levels compared to controls $(\mathrm{p}<0.01, \mathrm{p}<0.01$, $\mathrm{p}<0.01$ and $\mathrm{p}<0.05$, respectively). All subjects had renin and aldosterone levels within the normal range. Nevertheless, total renin concentrations were significantly increased in PCOS compared with controls $(\mathrm{p}<0.05)$. Aldosterone levels also tended to be higher, but this finding was not of statistical significance. Serum ACE activity did not differ significantly between PCOS patients and controls.

For patients with PCOS, there was a significant correlation between fasting insulin levels and those of total renin concentrations $(\mathrm{r}=0.305, \mathrm{p}<0.01)$, and free testosterone $(\mathrm{r}=0.384, \mathrm{p}=0.001)$. Similarly, HOMA-IR was positively correlated with total renin concentrations $(\mathrm{r}=0.366, \mathrm{p}<0.01)$ and free testosterone $(\mathrm{r}=0.352$, $\mathrm{p}<0.01$ ). Furthermore, a significant correlation was found between ACE activity and free testosterone levels $(\mathrm{r}=0.257, \mathrm{p}<0.05)$. Aldosterone correlated positively with high-sensitivity C-reactive protein in both PCOS patients $(\mathrm{r}=0.257, \mathrm{p}<0.05)$ and controls $(\mathrm{r}=0.248$, $\mathrm{p}<0.05)$.
Table 1. Demographic features and laboratory values of PCOS $(\mathrm{n}=41)$ and control $(\mathrm{n}=29)$ groups

\begin{tabular}{lccc}
\hline & $\begin{array}{l}\text { PCOS } \\
(\mathrm{n}=41)\end{array}$ & $\begin{array}{l}\text { Controls } \\
(\mathrm{n}=29)\end{array}$ & $\mathrm{p}$ \\
\hline Age, years & $25.4 \pm 3.9$ & $26.2 \pm 4.1$ & 0.24 \\
BMI & $36.9 \pm 6.11$ & $37.4 \pm 6.4$ & 0.21 \\
Waist-to-hip ratio & $0.90 \pm 0.1$ & $0.87 \pm 0.1$ & 0.13 \\
Ferriman-Gallwey score & $10.5 \pm 3.0$ & $4.8 \pm 1.7$ & $<0.001$ \\
Fasting glucose, mg/dl & $87.1 \pm 9.2$ & $90.6 \pm 8.2$ & 0.35 \\
Fasting insulin, mU/ml & $18.2 \pm 10.0$ & $15.6 \pm 8.0$ & 0.55 \\
HOMA-IR & $3.9 \pm 2.8$ & $3.5 \pm 2.7$ & 0.18 \\
& $3.4(1.2-10.4)$ & $3.1(1.3-9.9)$ \\
Plasma Na, mmol/l & $140.1 \pm 2.8$ & $140.6 \pm 2.7$ & 0.51 \\
Plasma K, mmol/l & $4.3 \pm 0.3$ & $4.4 \pm 0.3$ & 0.48 \\
Fibrinogen, mg/dl & $343.1 \pm 75.0$ & $357.2 \pm 98.0$ & 0.50 \\
hs-CRP & $5.1 \pm 4.4$ & $5.0 \pm 4.3$ & 0.19 \\
& & &
\end{tabular}

Data shown as mean $\pm \mathrm{SD}$, median and range (in parentheses). hs-CRP = High-sensitivity C-reactive protein.

Table 2. Hormonal profile in PCOS patients $(n=41)$ and controls $(\mathrm{n}=29)$

\begin{tabular}{|c|c|c|c|}
\hline & $\begin{array}{l}\text { PCOS } \\
(\mathrm{n}=41)\end{array}$ & $\begin{array}{l}\text { Controls } \\
(\mathrm{n}=29)\end{array}$ & $\mathrm{p}$ \\
\hline \multirow[t]{2}{*}{$\mathrm{FSH}, \mathrm{IU} / \mathrm{ml}$} & $6.3 \pm 7.0$ & $6.6 \pm 7.5$ & \multirow[t]{2}{*}{0.18} \\
\hline & $6.1(3.5-12.5)$ & $6.2(3.7-12)$ & \\
\hline \multirow[t]{2}{*}{$\mathrm{LH}, \mathrm{IU} / \mathrm{ml}$} & $8.8 \pm 6.4$ & $7.2 \pm 6.0$ & \multirow{2}{*}{$<0.01$} \\
\hline & $8.6(3.9-22.6)$ & $6.4(2.4-11.9)$ & \\
\hline \multirow[t]{2}{*}{ Prolactin, ng/ml } & $12.2 \pm 9.0$ & $11.9 \pm 8.9$ & \multirow[t]{2}{*}{0.36} \\
\hline & $11.2(6-31)$ & $10.9(6.2-28)$ & \\
\hline \multirow[t]{2}{*}{ Estradiol, pg/ml } & $69.3 \pm 50.4$ & $70.2 \pm 54.1$ & \multirow{2}{*}{0.14} \\
\hline & $68.1(13-133)$ & $68.4(12.5-146)$ & \\
\hline \multirow[t]{2}{*}{$\mathrm{P}, \mathrm{ng} / \mathrm{ml}$} & $1.74 \pm 2.4$ & $1.83 \pm 2.7$ & \multirow[t]{2}{*}{0.48} \\
\hline & $1.2(0.2-2.9)$ & $1.3(0.2-3.0)$ & \\
\hline 17-OHP, ng/ml & $1.5 \pm 0.7$ & $1.6 \pm 0.7$ & 0.28 \\
\hline Testosterone, ng/dl & $78.6 \pm 25.4$ & $45.3 \pm 18.5$ & $<0.01$ \\
\hline Free testosterone, $\mathrm{pg} / \mathrm{ml}$ & $3.9 \pm 1.4$ & $1.8 \pm 1.1$ & $<0.01$ \\
\hline DHEA-S, $\mu \mathrm{g} / \mathrm{dl}$ & $332.1 \pm 116.8$ & $275.8 \pm 94.5$ & $<0.05$ \\
\hline Cortisol, $\mu \mathrm{g} / \mathrm{dl}$ & $14.8 \pm 6.6$ & $13.3 \pm 4.3$ & 0.60 \\
\hline \multicolumn{4}{|l|}{ Aldosterone, $\mathrm{pg} / \mathrm{ml}$} \\
\hline (upright) & $228.9 \pm 125.5$ & $200.4 \pm 75.6$ & 0.26 \\
\hline Renin, pg/ml (upright) & $19.7 \pm 14.5$ & $12.9 \pm 9.0$ & $<0.05$ \\
\hline ACE & $27.7 \pm 15.3$ & $28.9 \pm 20.2$ & 0.89 \\
\hline
\end{tabular}

Data shown as mean $\pm \mathrm{SD}$, median and range (in parentheses). $\mathrm{FSH}=$ Follicle-stimulating hormone; $\mathrm{P}=$ progesterone; $17-\mathrm{OHP}=$ 17-hydroxyprogesterone; DHEA-S = dehydroepiandrosterone sulfate. 


\section{Discussion}

The present study demonstrated that obese women with PCOS had higher total renin concentrations (but within normal range) as compared to controls, consistent with findings from other trials $[19,20]$. On the other hand, reports regarding Ang II and aldosterone levels are controversial, with several studies demonstrating increased levels in women with PCOS, and others revealing similar Ang II and aldosterone concentrations both in patients with PCOS and controls [20-23]. However, we measured serum ACE activity but not Ang II in the current study. Serum ACE activity did not differ significantly between patients and controls $(p=0.15)$. Furthermore, no significant difference was found in aldosterone levels between PCOS and control groups. Our findings are consistent with other studies reporting higher levels of total renin but not Ang II and aldosterone concentrations in normotensive women with PCOS as compared to controls $[19,20]$.

Firstly, these differences may probably be due to the measurement of total renin concentrations. Although measurement of plasma renin is convenient for estimating the activity of the renin-angiotensin system, it may not necessarily reflect the real concentration of active renin. Several methodologies for the analysis of plasma renin have been reported. Immunoassays are available to quantify renin directly. However, these methods measure both active renin and prorenin and are susceptible to renin overestimation. Hence, the higher levels of total renin do not necessarily contribute to the activation of the systematic renin-angiotensin-aldosterone axis. Relevantly, similar renin activity both in young and overweight/ obese patients with PCOS and age- and BMI-matched controls has been reported [23]. However, there are other studies $[24,25]$ in which elevated plasma renin activity in patients with PCOS has been reported, but these studies involved hypertensive subjects and their PCOS patients had significantly higher systolic blood pressure values as compared to controls.

Secondly, evidence suggests that prorenin and the renin-angiotensin system may be linked to ovarian physiology [26]. Prorenin, an enzymatically inactive precursor of renin, is synthesized in the kidneys and extrarenal tissues such as adrenal glands, ovary, testis, and pituitary. Mature human ovarian follicles contain prorenin in high concentrations. Plasma prorenin, but not active renin, increases at midmenstrual cycle just after the LH surge [18]. Additionally, infertile women with PCOS have been shown to have higher baseline prorenin levels when compared with age- and weight-matched follicular phase controls [27].
In the present study, this could be an explanation for the higher levels of total renin determined by RIA, which measures both renin and prorenin as we could not measure prorenin levels.

There have been many attempts to show a role for prorenin in biological fluids. Furthermore, as is well known, the processing of prorenin to renin is confined to the kidneys. The very low angiotensin level in anephric subjects, despite plasma prorenin levels approximately being half of normal, indicate only a small contribution by prorenin to angiotensin formation in humans. Only $1 \%$ of prorenin is enzymatically active [28]. There is no evidence for its activation in biological fluids in experimental animal models [28]. This might explain why there were no significant differences in aldosterone levels and serum ACE activity between PCOS and the control group. Furthermore, urinary aldosterone excretion and Ang II-stimulated aldosterone are increased in overweight, compared with lean, normotensive adults [10]. Additionally, in studies demonstrating higher aldosterone levels in the PCOS group, women with PCOS had higher blood pressure values, insulin levels and HOMA index as compared to controls $[24,25]$. These results verified the close association between the inappropriate activation of the RAAS and above-mentioned features of metabolic syndrome accompanying PCOS $[24,25]$. In the present study, however, both groups included only obese subjects with IR and similar blood pressure values, another explanation for the similar aldosterone levels and serum ACE activity between groups.

On the other hand, renin and prorenin bind to the (pro)renin receptor. Nguyen et al. [29] acknowledged that the (pro)renin receptor could not be considered as a binding protein responsible for retaining renin in tissues because only $1 \%$ of soluble renin is expected to bind to the receptor. Sites of prorenin synthesis, such as the ovaries, testes, and adrenal glands may have higher picomolar concentrations of prorenin, but whether these concentrations are sufficient to bind to the (pro)renin receptor is unknown. Binding of renin and prorenin to the (pro)renin receptor initiates signal transduction mechanisms that are independent of participation by angiotensin peptides. More specifically, the binding of renin/prorenin via its receptor activates the complex of MAP-kinase pathways, that are also hyperactivated in IR states, including PCOS $[29,30]$. Therefore, the hyperreninemia in women with PCOS demonstrated in the present study may contribute to IR in PCOS either via further potentiation of the already activated MAP-kinase pathways, or via further inhibition of phosphatidylinositol-3 kinase activity. 


\section{Conclusion}

The present data demonstrate that obese women with PCOS have higher total renin levels, but not ACE activity and aldosterone levels, than age- and BMI-matched controls. New experimental approaches are required to investigate a potential role for prorenin in biological fluids that involves the (pro)renin receptor and is unrelated to Ang II.

\section{References}

1 Miller WL: Disorders of androgen synthesis - from cholesterol to dehydroepiandrosterone. Med Princ Pract 2005;14(suppl 1):5868.

2 Diamanti-Kandarakis E, Papavasiliou AG: Molecular mechanisms of insulin resistance in polycystic ovary syndrome. Trends Mol Med 2006;12:324-332.

-3 Poretsky L, Cataldo NA, Rosenwaks Z, et al: The insulin-related ovarian regulatory system in health and disease. Endocr Rev 1999;20: 535-582.

4 Nestler JE, Powers LP, Matt DW, et al: A direct effect of hyperinsulinemia on serum sex hormone-binding globulin levels in obese women with the polycystic ovary syndrome. J Clin Endocrinol Metab 1991;72:83-89.

-5 Ek I, Arner P, Rydén M, et al: A unique defect in the regulation of visceral fat cell lipolysis in the polycystic ovary syndrome as an early link to insulin resistance. Diabetes 2002;51:484 492.

-6 Mehta PK, Griendling KK: Angiotensin II cell signaling: physiological and pathological effects in the cardiovascular system. Am J Physiol Cell Physiol 2007;292:C82-C97.

7 Taniyama Y, Hitomi H, Hah A: Mechanisms of reactive oxygen species-dependent downregulation of insulin receptor substrate- 1 by angiotensin II. Arterioscler Thromb Vasc Biol 2005;25:1142-1147.

8 Hitomi H, Kiyomoto H, Nishiyama A, et al: Aldosterone suppresses insulin signaling via the downregulation of insulin receptor substrate-1 in vascular smooth muscle cells. Hypertension 2007;50:750-755.

-9 Rossi GP, Belfiore A, Bernini G, et al: Body mass index predicts plasma aldosterone concentrations in overweight-obese primary hypertensive patients. J Clin Endocrinol Metab 2008;93:2566-2571.

10 Bentley-Lewis R, Adler GK, Perlstein T: Body mass index predicts aldosterone production in normotensive adults on a high-salt diet. J Clin Endocrinol Metab 2007;92:4472-4475.
11 Engeli S, Negrel R, Sharma AM: Physiology and pathophysiology of the adipose tissue renin-angiotensin system. Hypertension 2000; 35:1270-1277.

12 Cassis LA, Saye J, Peach MJ: Location and regulation of rat angiotensinogen messenger RNA. Hypertension 1988;11:591-596.

13 Ehrhart-Bornstein M, Lamounier-Zepter V, Schraven A: Human adipocytes secrete mineralocorticoid-releasing factors. Proc Nat Acad Sci USA 2003;100:14211-14216.

14 Goossens GH, Blaak EE, Van Baak MA: Possible involvement of the adipose tissue reninangiotensin system in the pathophysiology of obesity and obesity-related disorders. Obes Rev 2003;4:43-55.

15 Ailhaud G, Teboul M, Massiera F: Angiotensinogen, adipocyte differentiation and fat mass enlargement. Curr Opin Clin Nutr Metab Care 2002;5:385-389.

16 Caprio M, Feve B, Claes A, et al: Pivotal role of the mineralocorticoid receptor in corticosteroid-induced adipogenesis. FASEB J 2007; 21:2185-2194.

17 Rotterdam ESHRE/ASRM-Sponsored PCOS Consensus Workshop Group: Revised 2003 consensus on diagnostic criteria and longterm health risks related to polycystic ovary syndrome. Fertil Steril 2004;81:19-25.

18 Sealey JE, Cholst I, Glorioso N, et al: Sequential changes in plasma luteinizing hormone and plasma prorenin during the menstrual cycle. J Clin Endocrinol Metab 1987;65:1-5.

19 Diamanti-Kandarakis E, Economou FN, Livadas S, et al: Hyperreninemia characterizing women with polycystic ovary syndrome improves after metformin therapy. Kidney Blood Press Res 2009;32:24-31.

20 Hacihanefioglu B, Seyisoglu H, Karsidag K, et al: Influence of insulin resistance on total renin level in normotensive women with polycystic ovary syndrome. Fertil Steril 2000;73: 261-265.
21 Li X, Shen H, Ge X: Changes of plasma renin activity and angiotensin II levels in women with polycystic ovary syndrome (in Chinese). Zhonghua Fu Chan Ke Za Zhi 2000;35:586587.

22 Bernini GP, Bela S, Cionini R, et al: Aldosterone and renin plasma levels in young patients with polycystic ovary syndrome. Endocrine Abstr 2006;11:P692.

23 Cascella T, Palomba S, Tauchmanovà L, et al: Serum aldosterone concentration and cardiovascular risk in women with polycystic ovarian syndrome. J Clin Endocrinol Metab 2006; 91:4395-4400.

-24 Mejia-Montilla J, Reyna-Villasmil E, TorresCepeda D, et al: Plasma renin and aldosterone levels in obese and non-obese women with polycystic ovary syndrome (in Spanish). Endocrinol Nutr 2012;59:21-27.

25 Armanini D, Bordin L, Donà G, et al: Polycystic ovary syndrome: implications of measurement of plasma aldosterone, renin activity and progesterone. Steroids 2012;77:655-658.

26 Derkx FH, Alberda AT, Zeilmaker GH, et al: High concentrations of immunoreactive renin, prorenin and enzymatically-active renin in human ovarian follicular fluid. Br J Obstet Gynaecol 1987;94:4-9.

27 Morris RS, Wong IL, Hatch IE, et al: Prorenin is elevated in polycystic ovary syndrome and may reflect hyperandrogenism. Fertil Steril 1995;64:1099-1103.

28 Lenz T, Sealey JE, Lappe RW, et al: Infusion of recombinant human prorenin into rhesus monkeys: effects on hemodynamics, reninangiotensin-aldosterone axis and plasma testosterone. Am J Hypertens 1990;3:257-261.

29 Nguyen G, Delarue F, Burckle C, et al: Pivotal role of the renin/prorenin receptor in angiotensin II production and cellular responses to renin. J Clin Invest 2002;109:1417-1427.

30 Huang Y, Noble NA, Zhang J: Renin-stimulated TGF- $\beta 1$ expression is regulated by a mitogen-activated protein kinase in mesangial cells. Kidney Int 2007;72:45-52. 